\title{
ANALYSIS OF TRANSITION ZONES OF LAYERED COMPOSITE MATERIALS OBTAINED BY THE PULSE METHOD OF PROCESSING
}

\author{
${ }^{1}$ Yulia BONDARENKO, ${ }^{2}$ Duan XIAOYU \\ 'Zaporizhzhia National University, Zaporizhzhia, Ukraine, belokon.zp@gmail.com \\ ${ }^{2}$ Fujian Xiang Xin Co., LTD., Fuzhou, China, duanxiaoyu0158@163.com
}

https://doi.org/10.37904/metal.2021.4125

\begin{abstract}
The purpose of this work is to examine the structure of the transition zone of multilayer composites of dissimilar metallic materials obtained by the pulse method of metal processing and to establish the mechanism for the material bonding. In this work, a composite material obtained by explosion welding was used as an initial sample. The initial blanks for obtaining a layered composite material were a $1.5 \mathrm{~mm}$ thick plate made of steel $101 \mathrm{~mm}$ thick brass L60 and $5 \mathrm{~mm}$ thick copper M1, as well as a $7 \mathrm{~mm}$ thick plate made of steel 10 and 1.5 $\mathrm{mm}$ thick lead bronze (Pb-22\%, Sn - 1\%). In the first sample, brass and copper plates were welded onto a horizontal steel plate, and in the second sample, a bronze plate was welded onto a steel plate as a result of an impact caused by an explosion. Copper and steel do not have significant mutual solubility, but despite this, they have been successfully subjected to explosion welding. The examination of the weld zone using X-ray micro-spectral analysis showed that, along the waves, there are areas containing both welded materials, as well as areas of a sharp concentration transition. Analysis formed phases in the system showed that a ternary compound $\mathrm{Cu}+\alpha \mathrm{Fe}+\beta^{\prime}$ is formed in the steel-brass transition zone. $\mathrm{Zn}$ largely penetrates into copper, that is the diffusional penetration of brass into copper occurs, as well as active mass transfer of zinc, with a constant decrease in zinc concentration from the upper to the lower boundary.
\end{abstract}

Keywords: Pulse metal forming, composite material, copper, steel, zinc, transition zone

\section{INTRODUCTION}

At present, the study of the issues of improving the technologies for obtaining composite materials is of great interest in the development of modern mechanical engineering through solving the main problems of materials science. Traditional materials are unable to solve the tasks assigned to them, namely, to provide a high level of physical and mechanical and operational properties. The investigation of the properties of composite materials and physicochemical processes occurring in the contact zone of blanks during the pulse method of metal processing makes it possible to obtain materials with unique properties, which opens up many new possibilities for solving problems in mechanical engineering [1].

Composite materials made of dissimilar metals are of particular interest, because they complement each other and combine various properties, which determines a wide field of their possible applications. Thus, composite materials based on copper and steel integrate structural strength with a high melting point and thermal conductivity. As a result, we get a promising material that will help open up new opportunities, for example, in the manufacture of parts for units of electrothermal and heat exchange equipment.

Explosion welding is one of the types of impulse methods of metal processing, has a high-intensity short-term exposure and allows to obtain multilayer composite materials with improved properties, including high strength, corrosion-resistant and heat-resistant characteristics. The structure of the transition zone determines the bond strength of composite materials; therefore, it is this particular structure that is usually the object of research. Today, there are many opinions regarding the nature of the strength of the bond in explosion welding. 
Researchers working in this field did not find a common ground on this issue: hypotheses are being discussed such as local melting of materials in the transition zone with their subsequent mixing; severe plastic deformation of the boundary layers; the formation of new phases, etc. Apparently, the lack of consensus on structural changes in the transition zone is associated with the physical and mechanical properties of the materials being joined, their dimensions (thickness) and processing parameters [2-4].

The aim of the study was to examine the structure of the transition zone of multilayer composites of dissimilar metallic materials obtained by the pulse method of metal processing and to establish the mechanism for the material bonding.

\section{RESEARCH METHODOLOGY}

In this work, a composite material obtained by explosion welding was used as an initial sample. The initial blanks for obtaining a layered composite material were a $1.5 \mathrm{~mm}$ thick plate made of steel $101 \mathrm{~mm}$ thick brass L60 and $5 \mathrm{~mm}$ thick copper M1, as well as a $7 \mathrm{~mm}$ thick plate made of steel 10 and $1.5 \mathrm{~mm}$ thick lead bronze $(\mathrm{Pb}-22 \%, \mathrm{Sn}-1 \%)$. In the first sample, brass and copper plates were welded onto a horizontal steel plate, and in the second sample, a bronze plate was welded onto a steel plate as a result of an impact caused by an explosion.

For metallographic studies, special samples were cut out. The study of the contact zones of the explosionwelded sample materials was carried out using a NEOPHOT 2 optical microscope. The samples were examined using a SUPRA 40WDS INKA-350 X-ray microanalyzer at different points and by spectra on transverse metallographic sections. Figure 1 shows the structures of the transition zone of steel-bronze composite materials obtained by explosion welding.
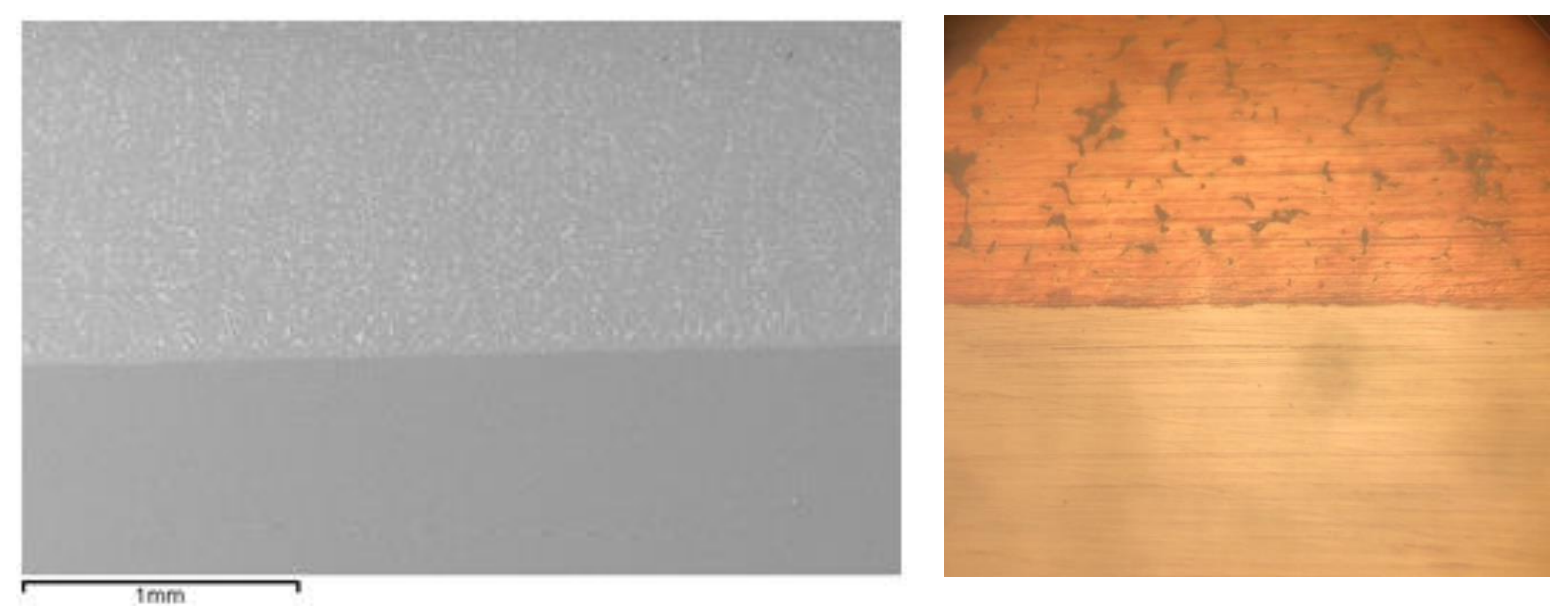

Figure 1 Microstructure of the transition zone of the composite material of the steel-bronze joint, $\times 200$

\section{RESULTS OF THE STUDY}

In steel, the usual ferrite-pearlite structure is observed, and a clear boundary between the materials is also visible without significant mutual dissolution. This nature of the interlayer boundaries of the connection of layers of dissimilar metals is associated with different densities of the materials being welded [5]. In the contact zone of steel and brass, traces of plastic deformation are noticeable, due to which the ferrite-pearlite structure is more distorted. In the structure of steel 10 , traces of the deformation flow of the metal after explosion welding are visible. One can also notice that pearlite grains in the welding contact zone take an elongated shape (Figure 1, b). 
The process of weld formation occurs without significant heating $\left(\sim 400{ }^{\circ} \mathrm{C}\right)$ [48]. That is, the metal does not melt, since the melting temperature of copper $\left(1085^{\circ} \mathrm{C}\right)$, steel $\left(1300-1500{ }^{\circ} \mathrm{C}\right)$, bronze $\left(930-1140{ }^{\circ} \mathrm{C}\right)$ and brass $\left(880-550^{\circ} \mathrm{C}\right)$ is much higher than this value. In the study [6], the formation of a joint during explosion welding is interpreted by the term "cold melting". This state can be achieved at sufficiently low temperatures, in contrast to melting. Cold melting is achieved by high pressure values during explosion, as a result of which the number of nonequilibrium vacancies increases and saturates the deformed body in almost the same way as during melting. Also in the works [7,8], the absence of molten zones is explained by the fact that copper has a high thermal conductivity, that is, it absorbs the heat released during explosion welding, thereby preventing the metal from melting.

Figure 2 shows the structure of the transition zone of the brass-copper composite material. In this area of interaction, the so-called "waves" are observed in the contact zone of the welded materials, which have a brighter character of interaction. This effect can be attributed to the relatively higher ductility of copper and brass compared to steel. The boundary of the concentrated transition is less smoothed, since copper and brass have mutual solubility, because they are related metals.

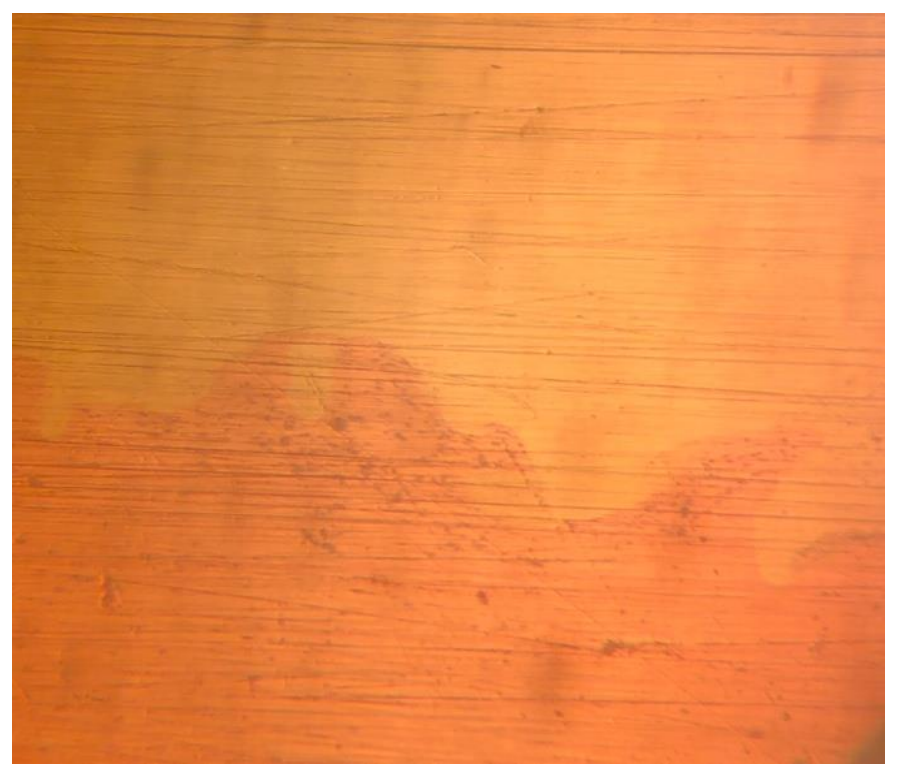

Figure 2 Microstructure of the transition zone of the joint of the brass and copper composite material, $\times 200$

In brass, banded structures elongated in the direction of deformation are observed. Having studied the state diagram of $\mathrm{Cu}-\mathrm{Zn}$, it was found that the phase component has a structure based on a ternary compound, namely, a $\beta$-solid solution based on a CuZn compound with an electronic type of bond (number of electrons = $3 / 2$ ) has a simple cubic volume-centered lattice. At a temperature of $454-468{ }^{\circ} \mathrm{C}$, the ordered arrangement of atoms is preserved, and at higher temperatures, the zinc and copper atoms will be located statistically in a volume-centered lattice. The ordered $\beta$-solid solution is denoted as $\beta^{\prime}$. Obviously, during the process of plastic deformation, an anomalously fast mass transfer of copper occurs in the direction from the brass to the copper part of the composite, which can explain the occurrence of this phase. The nature of the microstructure in the brass zone directly adjacent to the copper zone indicates the wave nature of mass transfer, which was expressed in the formation of successive transverse banded structures regularly located along the transition zone $[9,10]$.

Thus, the separation of particles of interacting materials and their mutual transfer over considerable distances can be explained using the theory of plastic deformation, which describes the processes as the interaction of mesovolumes (groups of grains, surfaces) under conditions of short-term and intense loading. In Figure 3, we see a wave-like structure of contact of steel-brass-copper materials obtained by explosion welding. 


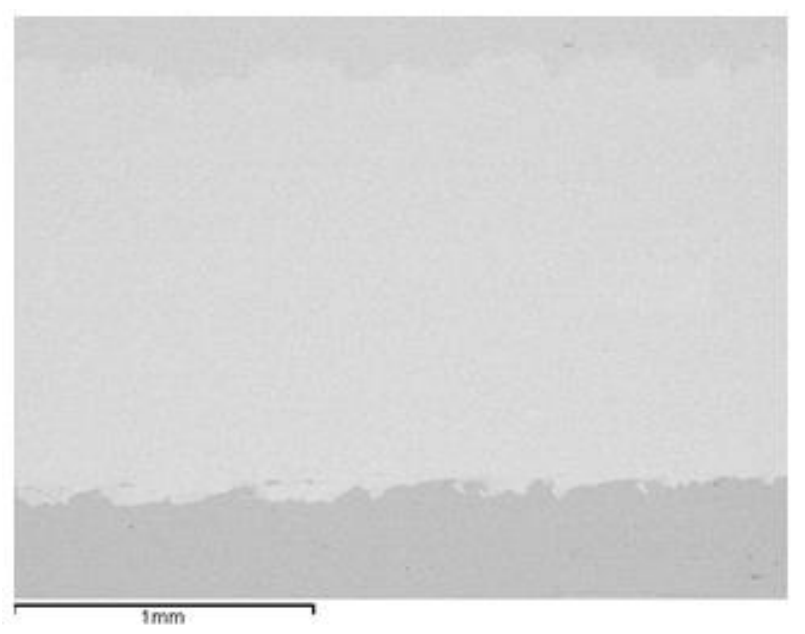

Figure 3 Examination of transition zones of the composite material of steel-brass-copper by the spectral point method

Copper and steel do not have significant mutual solubility, but despite this, they have been successfully subjected to explosion welding. The examination of the weld zone using X-ray micro-spectral analysis showed that, along the waves, there are areas containing both welded materials, as well as areas of a sharp concentration transition (Figure 4).
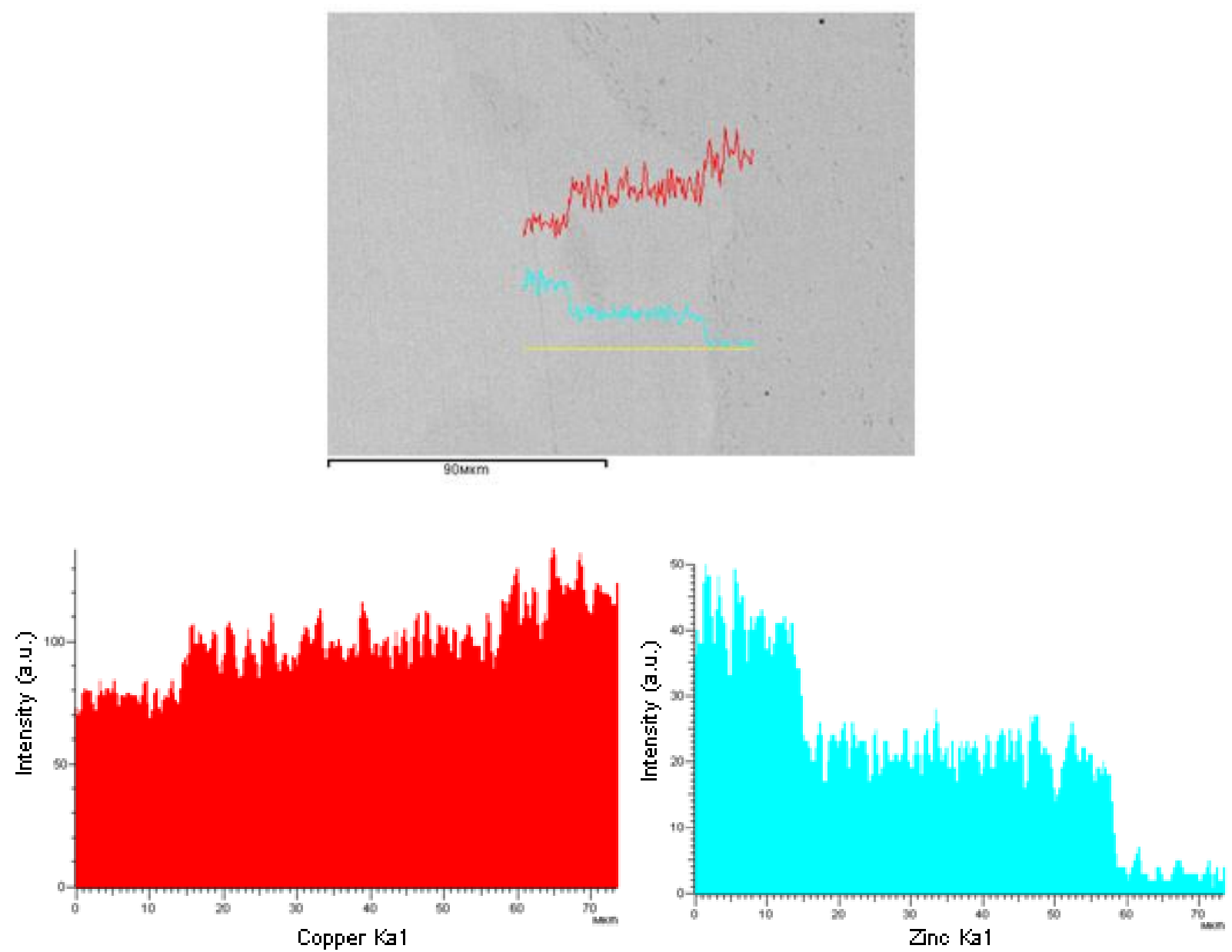

Figure 4 Distribution of elements in the transition zone of steel-brass composite material 
As a result of quantitative analysis, it was found that the chemical composition in mass ratios is: (spectrum 1) 0,08\%Fe, 99,60\%Cu, 0,31\%Zn; (spectrum 2) 63,46\%Cu, 36,54\%Zn; (spectrum 3) 62,43\%Cu, 37,57\%Zn; (spectrum 4) 98,61\%Fe, 0,53\%Cu, 0,41\%Zn,0,46Mn; (spectrum 5) 99,52\%Fe, 0,09\%Cu, 0,39\%Mn.

Analysis of the three-component phase diagram of $\mathrm{Fe}-\mathrm{Cu}-\mathrm{Zn}$ with the formed phases in the system showed that a ternary compound $\mathrm{Cu}+\alpha \mathrm{Fe}+\beta^{\prime}$ is formed in the steel-brass transition zone (Figure 5). In the study [11], the author explains this by the fact that in the process of explosion welding there is a convergence of particles at distances close to interatomic, as well as mutual mixing of moving surface layers of metals.

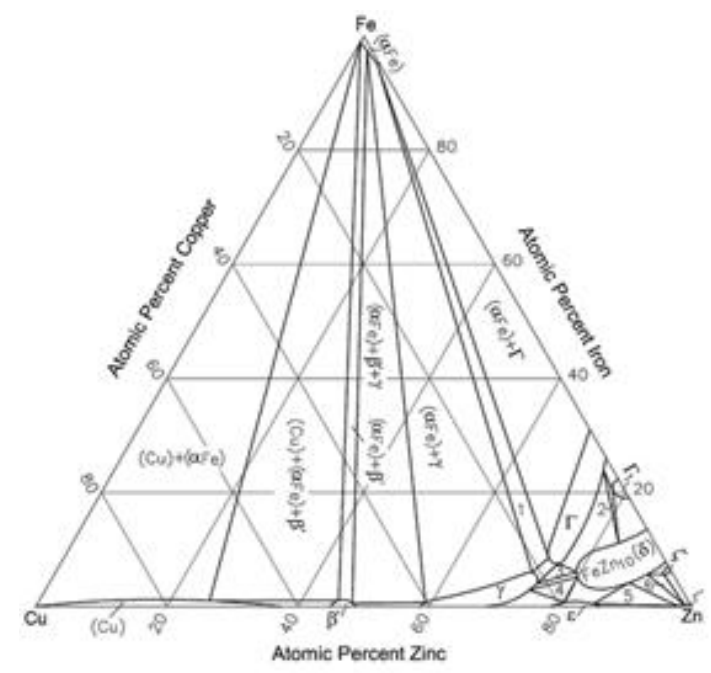

Figure 5 The diagram of the Fe-Cu-Zn: $1-(\alpha F e)+\gamma+\Gamma ; 2-F e Z n_{10}+\Gamma+\Gamma_{1} ; 3-F e Z n_{10}+\gamma+\Gamma ; 4-F e Z n_{10}+\gamma+\varepsilon$; $5-\mathrm{L}+\mathrm{FeZn} \mathrm{n}_{10}+\varepsilon ; 6-\mathrm{L}+\mathrm{FeZn} 10+\zeta$

For the accuracy of the obtained results, the X-ray spectral microanalysis was performed along the line. On the left side of the scanning trajectory, zinc peaks are highlighted, which is confirmed by the crystallization of the transition zone. In this area of the image (Figure 6), you can see the distribution of copper and zinc over the cross section of the sample.
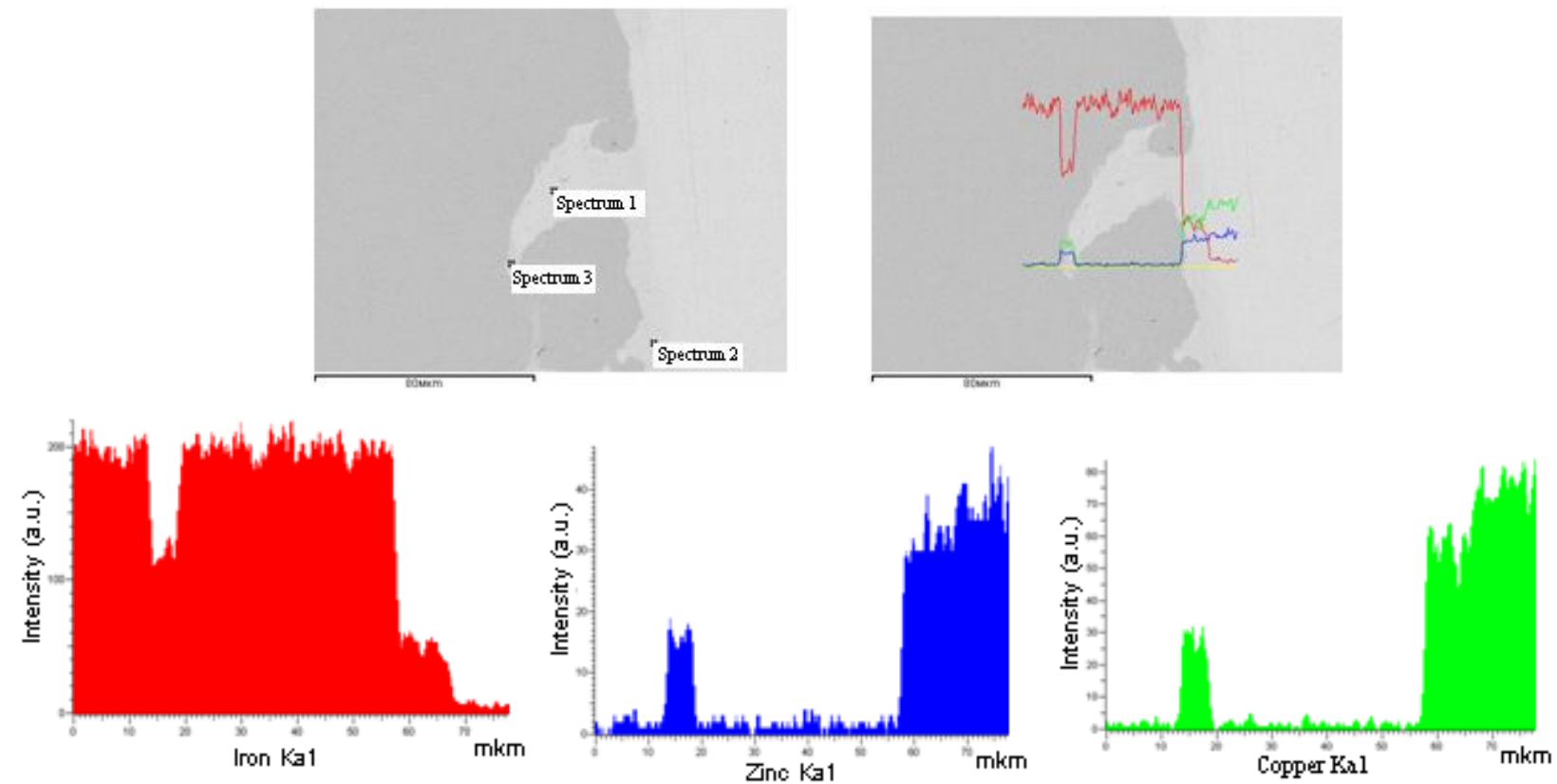

Figure 6 Distribution of elements in the transition zone for a copper-brass composite material 
On the right, there is pure brass, where the concentration of copper and zinc is high. Closer to the contact zone of copper, zinc and iron formed by explosion welding, the copper content drops sharply, but then we see a jump in this indicator, which means that brass has penetrated into steel through active mass transfer. $\mathrm{Zn}$ largely penetrates into copper, that is the diffusional penetration of brass into copper occurs, as well as active mass transfer of zinc, with a constant decrease in zinc concentration from the upper to the lower boundary. As a result of quantitative analysis, it was found that the quantitative composition in weight ratios is: (spectrum 1) $24,48 \% \mathrm{Fe}, 47,20 \% \mathrm{Cu}, 28,83 \% \mathrm{Zn}$; (spectrum 2) 17,84\%Fe, 51,85\% Cu, 30,30\%Zn; (spectrum 3) 57,35\%Fe, $26,74 \% \mathrm{Cu}, 15,58 \% \mathrm{Zn}$.

\section{CONCLUSION}

Copper and steel do not have significant mutual solubility, but despite this, they have been successfully subjected to explosion welding. The examination of the weld zone using X-ray micro-spectral analysis showed that, along the waves, there are areas containing both welded materials, as well as areas of a sharp concentration transition. Analysis formed phases in the system showed that a ternary compound $\mathrm{Cu}+\mathrm{\alpha Fe}+$ $\beta^{\prime}$ is formed in the steel-brass transition zone. Zn largely penetrates into copper, that is the diffusional penetration of brass into copper occurs, as well as active mass transfer of zinc, with a constant decrease in zinc concentration from the upper to the lower boundary.

\section{REFERENCES}

[1] ZABELIN, I.V., PROTSENKO, V.M. Status of non-ferrous metal industry in Ukraine and problems in its development. Metallurgicheskaya i Gornorudnaya Promyshlennost. 2003, vol. 4, pp. 75-78.

[2] SEREDA, B., KRUGLYAK, I., KRUGLYAK, D., SEREDA, D., SHEYKO, S. The researching of deformational parameters at copper alloys rolling with protective coatings. In: Materials Science and Technology Conference and Exhibition. Columbus: MS\&T, 2011, pp. 1710-1714.

[3] HRYHORIEV, S., PETRYSHCHEV, A., KRUPEY, K., ANDREEV, A., KATSCHAN, A., STEPANOV, D., MANIDINA, Y., RYZHKOV, V., BERENDA, N., MATIUKHIN, A. Study of environmentally safe obtaining of molybdenum-based alloying material by solid phase extraction. Eastern-European Journal of Enterprise Technologies. 2017, vol 6, no. 12(90), pp. 35-40.

[4] BELOKON, K., BELOKON, Y. The usage of heat explosion to synthesize intermetallic compounds and alloys. Ceramic Transactions. 2018, vol. 261, pp. 109-115.

[5] SEREDA, B., ZHEREBTSOV, A., KRUGLYAK, I., BELOKON', Y., SAVELA, K., SEREDA, D. The retrieving of heat-resistant alloys on intermetallic base for details of gas turbine engine hot track in SHS conditions. In: Materials Science and Technology Conference and Exhibition. Houston: MS\&T, 2010, pp. 2097-2102.

[6] SEREDA, B., SEREDA, D., BELOKON, Y. Investigation of corrosion and oxidation of Y-TiAl alloys obtained in self propagating high temperature synthesis. In: Materials Science and Technology Conference and Exhibition. Columbus: MS\&T, 2015, pp. 1249-1255.

[7] SEREDA, B., KRUGLYAK, I., KRUGLYAK, D., SEREDA, D., SHEYKO, S. The protective coverings obtaining on copper alloys in condition of SHS. In: Materials Science and Technology Conference and Exhibition. Houston: MS\&T, 2010, pp. 2115-2119.

[8] BELOKON, K. V., BELOKON, Y. A., KOZHEMYAKIN, G. B., MATUKHNO, E. V. Environmental assessment of the intermetallic catalysts utilization efficiency for deactivation of the pollutants emitted by electrode production enterprises. Naukovyi Visnyk Natsionalnoho Hirnychoho Universytetu. 2016, no. 3(153), pp. 87-94.

[9] BONDARENKO, Y. Consistent patterns of silicide coatings formation on titanium at various rates of mixture heating. Metallurgical and Mining Industry. 2015, vol. 7, no. 10, pp. 205-207.

[10] CHEILYTKO, A.A., ILIN, S.V., NOSOV, M.A. Creation of effective metallic thermal insulation constructions. Naukovyi Visnyk Natsionalnoho Hirnychoho Universytetu. 2017, no. 6, pp. 103-108.

[11] SHAPOVAL, A., DRAHOBETSKYI, V., SAVCHENKO, I., GURENKO, A., MARKOV, O. Profitability of production of stainless steel+zirconium metals combination adapters. Key Engineering Materials. 2020, vol.864, pp. 285-291. 